\title{
Characterization of Type I and III Collagen Fibers in the Stroma of Female Canine Mammary Tumors
}

\section{Hernando Daniel Acevedo ${ }^{1 *}$, Sirley Adriana Ortiz ${ }^{2,3}$, Polyana Galvão Coelho ${ }^{2}$, Iang SCHRONILTGEN RONDÓN-BARRAgÁN ${ }^{1}$, MARLENE ISABEL VARGAS ${ }^{2}$}

${ }^{1}$ Faculty of Veterinary Medicine and Zootechnics, University of Tolima (UT), Ibagué-Tolima, Colombia (Acevedo, Rondón-Barragán); 'Department of Veterinary, Federal University of Viçosa (UFV), Viçosa Minas Gerais, Brazil (Vargas, Ortiz, Coelho); ${ }^{3}$ Program of Veterinary Medicine and Zootechnics, University of Santander (UDES), Campus Valledupar, Colombia (Ortiz).

\begin{abstract}
There are a significant number of patients with canine mammary tumors (CMTs) whose outcome and prognosis are not predicting with the clinical indicators and current histopathological grading (I, II, III), where grade III mammary carcinomas have a 21 -fold greater risk of death than grade I and II tumors. Therefore, it is main to use complementary diagnostic methods to improve histological classification in these cases. The presence of type I (Coll-I) and III (Coll-III) collagen in the tumor stroma is related to metastasis from human breast cancer. From paraffin-embedded samples (FFPE) of the stroma of canine mammary gland carcinomas (CMGCs), we describe the characterization of type I and III collagen fibers in 10 samples of each histological grade $(n=30)$, using Picrosirius red (PSR) staining under polarized light to evaluate its relationship with histological grading. The Coll-I fibers showed different lengths, disposition, and thickness in all tumor grades with a random distribution. In the three histological grades, the Coll-III fibers showed a lower expression than the Coll-I fibers, showing the highest expression of Coll-III in grade I, decreasing its gradual percentage in grades II and III $(P<0.0001)$. Our results indicate that the decrease of Coll-III in the tumor stroma is inversely proportional to the increase in the grading of CMGCs. Therefore, we suggest that PSR can be a complementary method that helps to support the grading of CMGCs in a diagnostic laboratory workflow.
\end{abstract}

Keywords | Oncology, Mammary neoplasm, Canine, Picrosirius

\footnotetext{
Received | March 26, 2021; Accepted | September 25, 2021; Published | December 01, 2021

*Correspondence | Hernando Daniel Acevedo, Faculty of Veterinary Medicine and Zootechnics, University of Tolima (UT), Santa Helena Highs I, 730006299, Ibagué, Colombia; Email: hjacevedo@ut.edu.co

Citation | Acevedo HD, Ortiz SA, Coelho PG, Rondón-Barragán IS, Vargas MI (2022). Characterization of type I and III collagen fibers in the stroma of female canine mammary tumors. Adv. Anim. Vet. Sci. 10(1): 78-84.

DOI | http://dx.doi.org/10.17582/journal.aavs/2022/10.1.78.84

ISSN (Online) | 2307-8316; ISSN (Print) | 2309-3331
}

Copyright (C) 2022 Acevedo et al. This is an open access article distributed under the Creative Commons Attribution License, which permits unrestricted use, distribution, and reproduction in any medium, provided the original work is properly cited.

\section{INTRODUCTION}

$\mathrm{C}$ anine mammary tumors (CMTs) are the most common neoplasia in female dogs, with a higher prevalence in pure breeds (Misdorp, 2002). Its development is related to the low expression of the progesterone and estrogen produced in the ovaries and their receptors in breast cancer tissue (Chang et al., 2009) in addition, it's has been associate with the age of the animal (Benavente et al., 2016). Currently, there are several diagnostic tools for canine mammary gland carcinomas (CMGCs) like infrared breast thermography, ultrasound, and diagnostic cytology by fine-needle aspiration (Simon et al., 2009; Pavelski et al., 2015; Soler et al., 2016). Nevertheless, histopathology is the method to confirm the diagnosis with histological grading of mammary tumors (Tavasoly et al., 2013; Soler et al., 2016). The histopathological classification of canine mammary neoplasms is by the three-grade classification system (i.e., I, II, III) proposed for breast tumors in human medicine (Elston and Ellis, 1991). This scale 
assesses tubule formation, nuclear pleomorphism, and mitotic count, defining the patient's prognosis (Peña et al., 2013). Grade III mammary carcinomas have a 21-fold greater risk of death than grade I and II tumors in canines (Karayannopoulou et al., 2005). Authors report that at least $50 \%$ of CMTs are malignant, while others describe percentages ranging from 26\% to $73 \%$ (Perez et al., 2000).

Studies have shown that breast cancer in humans and murine models showed an interaction between tumor cells and extracellular matrix (ECM) proteins (Lyons et al., 2011; Provenzano et al., 2008). ECM is mainly composed of proteoglycans and fibrous proteins (e.g., collagen, elastin, fibronectin, and laminin) (Theocharis et al., 2016). Mammary acini can coordinate their disorganization toward a malignant phenotype through long-range mechanical interactions with a collagen matrix, accelerating the transition to an invasive phenotype (Shi et al., 2014). On the other hand, tension homeostasis is describing as the decisive factor for the malignant phenotype in tumors, where the chronic increase in cytoskeletal tension, mediated by the sustained rigidity of the matrix (i.e., the increase in collagen fibers) or by the elevation of the extracellular signal-regulated kinase (ERK) and Rho kinase activity (oncogene amplification), if of sufficient magnitude and duration, could drive the assembly/ stabilization of focal adhesion (mediated by integrins) to enhance growth and perturb tissue organization, promoting malignant transformation of a tissue (Paszek et al., 2005).

Collagen plays a fundamental role in the tumor microenvironment through its ability to modulate physical, biochemical, and biomechanical cues perceived by both tumor cells and cancer-associated stromal cells producing tumor stiffness (Brisson et al., 2015; Golaraei et al., 2016; Levental et al., 2009; Maller et al., 2013; Provenzano et al., 2006), and also changes in its pattern to align and increasing its density progressively (Jones et al., 2019; Luparello, 2013; Provenzano et al., 2006). In the same way, Wei et al. (2015) showed that an increase in matrix stiffness by collagen fiber alignment activates epithelial-mesenchymal transition-inducing transcription factor TWIST1 and reduced expression of G3BP2 (Ras GTPase-activating protein-binding protein 2) together predict poor survival in breast tumors.

Specifically, the deposition of type I collagen (Coll-I) can be determinant in the tumor microenvironment regulating proliferation, decreasing cell adhesion, survival, migration, and invasion (Badaoui et al., 2018; Koening et al., 2006). Furthermore, Coll-I fibers are the main structural component of the stroma of various tumors and are considered biomarkers of metastasis from breast cancer to lung in humans (Kakkad et al., 2012).
The collagen plays a crucial role in modulating the biological behavior of CMTs, and there is evidence that tumorassociated collagen signatures (TACS) defined by secondgeneration harmonic imaging (SHG) that are predictive of aggressive biologically behavior and poor prognosis (Case et al., 2017; Garcia et al., 2021). Picrosirius (PSR) is a stain that highlights the collagen present in the stroma of the tissues employing the birefringence of the collagen fibers, detected under polarized light (Rittié, 2017). This technique allows the evaluation of collagen fibers involving their alterations through morphometric techniques such as spot planimetry and color segmentation (Bedoya et al., 2019; Coelho et al., 2018; Coleman, 2011). Studies in canine tumor stroma have found differences in Coll-I and type III (Coll-III) collagen fibers using PSR (Bedoya et al., 2016; Calderon et al., 2019). Due to the decisive role of collagen in modulating the development and progression of breast cancer in canine females, the study of tumor-stroma can help to elucidate potential therapeutic targets for tumor control (Case et al., 2017). In veterinary medicine, there are no reports of Coll-I and Coll-III fibers density by PSR stain in CMGCs. This study aims to quantify the Coll-I and Coll-III fibers in the stroma of CMGCs and their relationship with neoplasia grading.

\section{MATERIALS AND METHODS}

\section{SAMPLE COLLECTION AND HISTOPATHOLOGY}

30 paraffin-embedded (FFPE) samples with the diagnosis of CMGCs were used in this study for histopathological grading, PSR staining, and microphotographic record of ten random fields to the intratumoral regions with a magnification of 200X. Samples were obtained from the archive of the year 2017 of the Veterinary Histopathology Laboratory, DVT, UFV, Viçosa, MG, Brazil. All samples were collected from female dogs and for tumor grading they were not discriminated by age, race, or reproductive status. This study was approved by the Ethics Committee for the use of animals in research (Ceua), Federal University of Viçosa (UFV) (68/2019).

In multi-head microscopy, two veterinary pathologists reexamined the selected samples to confirm the diagnosis and the histopathological classification was performed in grades I, II, and III according to the Consensus for the Diagnosis, Prognosis and Treatment of Canine Mammary Tumors (Cassali et al., 2014). Histological sections of 3 $\mu \mathrm{m}$ thickness from the FFPE samples were prepared to staining with the histochemical Picrosirius red (PSR) staining for the observation and quantification of the Coll-I and Coll-III fibers.

The 30 CMGCs samples from female dogs included 8 mixed breeds, 5 Poodle, 2 Dalmatian, 2 German Shepherd, 
1 Labrador retriever, 1 Pinscher, and 1 Bull Terrier, no information related to breed was obtained in 10 samples. The median age at the time of diagnosis was $9 \mathrm{y}$ (range: 5-16 y).

\section{Picrosirius Red (PSR) STAINING}

Histological samples were deparaffinized in xylene and rehydrated in alcohol. Subsequently, PSR staining was performed using a commercial kit (Histokit TM, Easypath, SP, Brazil), according to the manufacturer's instructions. The slides were examined and ten random fields with 200X magnification were photographed using an optical microscope with polarized light (Olympus BX-53 ${ }^{\circledR}$, Japan) connected to an Olympus Qcolor 3 camera (Brazeiss Representações Ltda, São Paulo, SP, Brazil). QCapture Pro 6 software (Version 6.0.0.605, Qimaging, Canada https:// www.qimaging.com/support/downloads/qcappro60.php) was used to capture the images. Type I collagen fibers were considered to represent red-orange birefringence and type III green or yellow-green birefringence collagen fibers (Coleman, 2011).

\section{PSR INTERPRETATION}

Image analysis performed by color segmentation with Image J $1.49 \mathrm{v}$ software (National Institutes of Health, available online: https://imagej.nih.gov/ij/index.html) using the Threshold Plug-in Color. The values for each type of collagen in the Threshold Color were standardized for all images as follows: Hue 0-40 for the color red (type I collagen) and 45-120 for the color green (type III collagen), saturation 0-255 and brightness 5-225 for both types of collagen (Bedoya et al., 2016). Collagens data were export in an Excel spreadsheet (Excel version 15.35; Microsoft Corporation, Redmond, WA) for further statistical analysis.

\section{STATISTICAL ANALYSis}

The data were analyzed using descriptive statistics, and the differences in the area (\%) of type I and III collagen fibers in the three grades of CMGCs were assessed by the KruskalWallis test using Dunn`s test as post hoc. Statistical analysis was done using GraphPad Prism software v 8.0 (GraphPad Software Inc., La Jolla, CA, USA). Differences were considered statistically significant when $P<0.05$.

\section{RESULTS AND DISCUSSION}

In this study, we identify, characterize, quantify and compare the Coll-I and Coll-III fibers in the threedegree intratumoral areas of CMGCs using PSR staining. Among the 30 cases of mammary neoplasm evaluated, $5,1 \%$ were carcinoma in mixed tumor $(n=17), 2,1 \%$ solid carcinoma $(n=7), 1,2 \%$ tubular carcinoma $(n=4)$ and $0,6 \%$ papillary carcinoma $(n=2)$. In the three grades of CMGCs,
Coll-I fibers were dominant showed different thicknesses, sizes, and a discontinuous length with marked orange and red birefringence showing fragmented areas in medium proportion, distributed throughout the neoplastic area. In the tumor stroma, mainly in the central areas, fibers of different sizes were observed that delimited areas with groups of tumor cells (Figure 1). Coll-III fibers were observed in the middle of Coll-I fibers with a marked green-yellow birefringence, in a random distribution, forming discontinuous and fragmented thick bands of different lengths and sizes, thinner fibers were surrounding tumor acini in central areas (Figure 1).

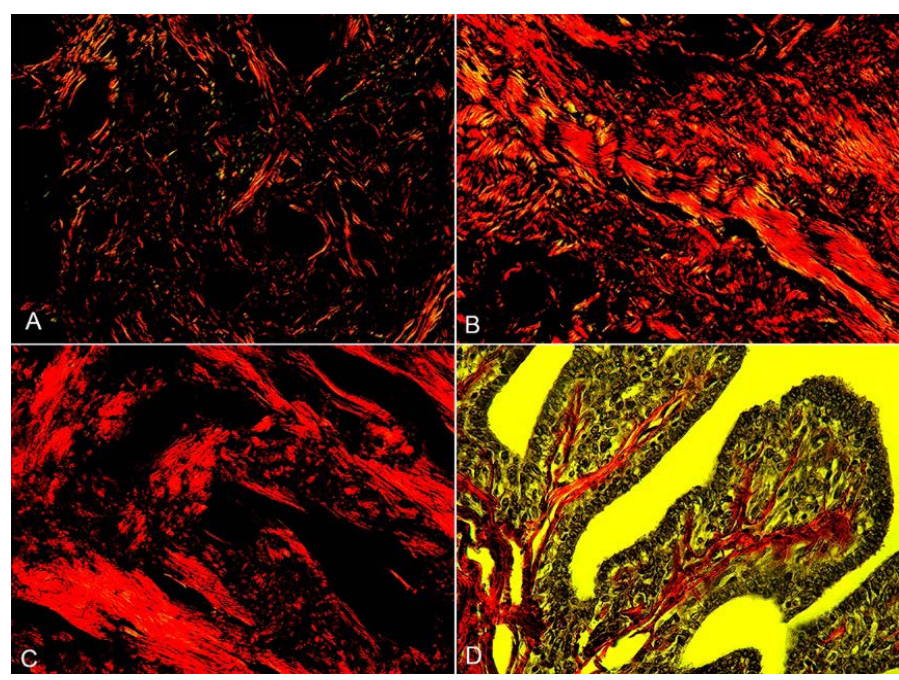

Figure 1: Collagen fibers in grades I, II, and III of the CMGCs (canine mammary gland carcinomas). A, CMGCs grade I, collagen fibers in the stroma appear with red-orange birefringence (Coll-I) and green birefringence (Coll-III). B, CMGCs grade II, a predominance of Coll-I fibers can observe. C, CMGCs grade III, note the formation of dense collagen bands of Coll-I. D, Collagen fibers in pedunculated papillary structures in CMGCs, under low polarized light. PSR staining. 200X.

The analysis of the data revealed that there was no significant statistical difference in the expression of Coll-I between the three grades of CMGCs $(P>0.05)$ (Figure 2). Regarding the proportion of Coll-III, there were differences in the expression between grades I - III, and II - III $(P<0.05)$ (Figure 2). The proportion of the collagen studied may be influenced by the activity of ECM remodeling enzymes that contribute to cancer progression (Green and Lund, 2005). Associating with the expression of proteases such as matrix metalloproteinases (MMPs) (Bonnans et al., 2014), the MMP-2, -3, -9, -14 being the most important in breast cancer invasion (Oskarsson, 2013). Causing collagen proteolysis as a mechanism of tumor invasion (Insua-Rodríguez and Oskarsson, 2016).

The microscopic morphological characteristics and arrangement of the collagen fibers observed in this study 
are consistent with previous findings in the stroma of breast carcinomas (Martins et al., 2002). Our results indicate a higher percentage of Coll-I fibers in CMGCs, in agreement with reports of collagen content in tumor stroma in dogs using PSR, including canine squamous cell carcinomas (SCC) classified as well and poorly differentiated that showed a percentage of approximately $30 \%$ of Coll-I fibers and less than 1\% of Coll-III fibers in both grades of SCC, low and high (Bedoya et al., 2016). Likewise, a higher proportion of Coll-I has been described in canine neoplastic prostate compared with normal prostate, without significant statistical differences between the two types of collagen (Calderon et al., 2019). However, differential staining of collagen fiber has shown dissociation (Kauppila et al., 1998). This dissociation may be because that type III collagen decreases with the increase in tumor malignancy as we showed in our results. Coll-I fibers are the most abundant component of ECM in different types of cancer and with higher expression in metastatic tumors (van-Kempen et al., 2003). Its fibers have been reported as biomarkers of pulmonary metastasis in murine models with mammary gland tumors (Provenzano et al., 2008).
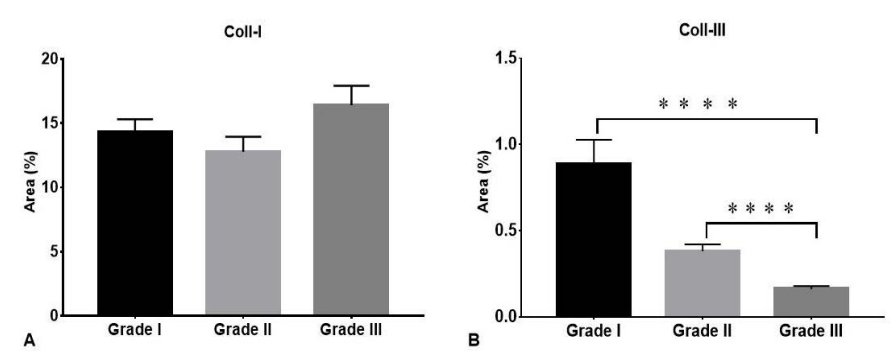

Figure 2: Density of collagen type I and III in three grades of CMGCs. Coll-I (Collagen type I), Coll-II (Collagen type III). ${ }^{* * * * *} P<0.0001$.

The lack of a defined boundary between tumor-stroma and the width of the collagen fiber is associated with a decrease in patient survival considering related factors such as tumor grade (Case et al., 2017), also is related that the more aggressive carcinomas present shorter collagen fibers in comparison with the less aggressive (Garcia et al., 2021). At the genetic level, analysis of stromal mRNA level in normal and tumoral mammary tissue indicated that genes coding for Coll-I, fibroblast activation protein, and $\alpha$-smooth muscle actin are highly expressed in tumor stroma than in normal tissues (Ettlin et al., 2017). In addition, mRNA levels of type I and III procollagen showed higher as the malignancy of the neoplasia increases in human breast cancer, indicating Coll-I and CollIII synthesis as a possible pathway for tumor invasion (Kauppila et al., 1998).

Although we do not study the survival rate concerning the proportion of collagen and the grades of CMGC, breast cancer in human patients showed that a high expression of Coll-III is related to a higher survival rate (Beck et al., 2008). In this study, the percentage of Coll-III fibers in the CMGCs gradually decreased as the grade of the tumor increased, obtaining less expression of these fibers in the grade III tumor. Regarding the degree of malignancy, breast cancer grade III has lower rates of survival in humans, same as reported in dogs (Moriggi et al., 2018; Rasotto et al., 2017). On the other hand, the role of CollIII in breast cancer is still under investigation, its function in breast cancer cells of murine and human models has been evaluated in vitro, finding that it suppresses the pro-carcinogenic behavior of tumor cells limiting the growth of primary tumors and metastasis (Brisson et al., 2015). According to the above and our results, we suggest that theoretically, those animals with lower CollIII expression that were those with the highest CMGCs degree would be less likely to survive as a result of the metastatic invasion of cancer caused by the progressive loss of Coll-III. This invasion occurs because cancer cells interact directly with cancer-associated fibroblasts that are components of the stroma, using an $\alpha 5 \beta 1$ integrin that causes increased migration of cancer cells to fibroblast networks (Miyazaki et al., 2019). Supporting the previous findings that activation of focal adhesion kinase fak, an integrin-mediated signaling molecule, is pivotal for the development of malignant tumors (McLean et al., 2004).

Complementary diagnostic methods may be necessary to improve the grading of the CMGCs tumors (Case et al., 2017), there are a significant number of canine patients whose outcomes and prognosis are not predicted with current clinical and histopathological indicators (Karayannopoulou et al., 2005; Oskarsson, 2013). Therefore, we suggest that PSR can be a complementary method that helps to support the grading of CMGCs in a diagnostic laboratory workflow. In addition, serial tumor sampling would allow the characterization of the collagen fiber expression in CMGCs and may be useful as a predictive tool for patient prognosis. Finally, this study may represent a basis for prospective and other quantification studies of Coll-I, Coll-II, and Coll-III in CMGCs, with a greater number of samples of each tumor grade, using different breeds and evaluating neoplastic behavior to determine their possible differences. PSR staining showed the microstructural changes and distribution of collagen fibers in the ECM of the CMTs that correlated with the grade of tumor differentiation. There was a greater predominance of Coll-I in the different degrees of CMGCs, but no difference was found in the expression of this type of collagen among these (Figure 2). The highest expression of Coll-III was observed in grade I, decreasing its gradual percentage in grades II and III. Although the survival rate was not evaluated in this study as mentioned above, the PSR staining showed that those patients with 
a lower proportion of Coll-III in CMGCs are potentially considered with a higher degree of malignancy and poor prognosis.

\section{CONCLUSIONS}

The Coll-I fibers showed different lengths, disposition, and thickness in all tumor grades with a random distribution. In the three histological grades, the Coll-III fibers showed a lower expression than the Coll-I fibers, showing the highest expression of Coll-III in grade I, decreasing its gradual percentage in grades II and III $(\mathrm{P}<0.0001)$. Our results indicate that the decrease of Coll-III in the tumor stroma is inversely proportional to the increase in the grading of CMGCs. Therefore, we suggest that PSR can be a complementary method that helps to support the grading of CMGCs in a diagnostic laboratory workflow.

\section{ACKNOWLEDGMENTS}

We thank the Pathology Laboratory of the Veterinary Department of the Federal University of Viçosa for allowing the use of the sample file and the use of its facilities to carry out this study. We also thank Dr. Francisco A. Uzal for his academic and technical contribution. This work was funded in part by the Coordenação de Aperfeiçoamento de Pessoal de Nivel Superior (Capes), Scholarship holder of the program Estudantes - Convênio de Pós- Graduação (PECPG), Conselho Nacional de Desenvolvimento Científico e Tecnológico (CNPq) - Brazil (CVZ - APQ00661-11 and CVZ - PPM-00222-13) and Fundação de Amparo a Pesquisa do Estado de Minas Gerais (FAPEMIG).

\section{CONFLICT OF INTEREST}

The authors have declared no conflict of interest.

\section{AUTHOR'S CONTRIBUTION}

All authors contributed equally to the manuscript.

\section{REFERENCES}

- Badaoui M, Mimsy-Julienne C, Saby C, van Gulick L, Peretti M, Jeannesson P, Morjani H, Ouadid-Ahidouch H (2018). Collagen type 1 promotes survival of human breast cancer cells by overexpressing Kv10.1 potassium and Orai1 calcium channels through DDR1-dependent pathway. Oncotarget, 9(37): 24653-24671. https://doi.org/10.18632/ oncotarget. 19065

- Beck AH, Espinosa I, Gilks CB, van de Rijn M, West RB (2008). The fibromatosis signature defines a robust stromal response in breast carcinoma. Lab. Invest., 88(6): 591-601. https://doi.org/10.1038/labinvest.2008.31

- Bedoya SAO, Conceição, LG, Viloria MIV, Loures FH, Valente FL, Amorim RL, Silva FF (2016). Caracterização de colágenos tipos I e III no estroma do carcinoma de células escamosas cutâneo em cães. Characterization of types I and III collagen in the stroma of cutaneous squamous cell carcinoma in dogs. Arq. Bras. Med. Vet. Zootec., 68(1): 147154. https://doi.org/10.1590/1678-4162-8484

- Bedoya SAO, Souza MV, Conceição LG, Viloria MIV, Valente FL, Loures FH, Moreira JCL, Coelho PGB (2019). Quantificação do colágeno dérmico equino por duas técnicas morfométricas: contagem de pontos e segmentação de cor. Quantification of equine dermal collagen by two morphometric techniques: point counting and color segmentation. Arq Bras. Med. Vet. Zootec., 71(3): 761-769. https://doi.org/10.1590/1678-4162-10487

- Benavente MA, Bianchi CP, Aba MA (2016). Canine mammary tumors: Risk factors, prognosis and treatments. J. Vet. Adv., 6(8): 1291-1300. https://doi.org/10.5455/ jva.20160916045115

-Bonnans C, Chou J, Werb Z (2014). Remodelling the extracellular matrix in development and disease. Nat. Rev. Mol. Cell. Biol., 15(12): 786-801. https://doi.org/10.1038/ nrm3904

-Brisson BK, Mauldin EA, Lei W, Vogel LK, Power AM, Lo A, Dopkin D, Khanna C, Wells RG, Puré E, Volk SW (2015). Type III collagen directs stromal organization and limits metastasis in a murine model of breast cancer. Am. J. Pathol., 185(5): 1471-1486. https://doi.org/10.1016/j. ajpath.2015.01.029

- Calderón LGR, Kobayashi PE, Vasconcelos RO, FonsecaAlves CE, Laufer-Amorim R (2019). Characterization of Collagen Fibers (I, III, IV) and Elastin of Normal and Neoplastic Canine Prostatic Tissues. Vet. Sci., 6(1): 22. https://doi.org/10.3390/vetsci6010022

- Case A, Brisson BK, Durham AC, Rosen S, Monslow J, Buza E, Salah P, Gillem J, Ruthel G, Veluvolu S, Kristiansen V, Puré E, Brown DC, Sørenmo KU, Volk SW (2017). Identification of prognostic collagen signatures and potential therapeutic stromal targets in canine mammary gland carcinoma. PLoS One, 12(7): e0180448. https://doi.org/10.1371/journal. pone. 0180448

-Cassali GD, Lavalle GE, Ferreira E, Estrela-Lima A, De Nardi AB, Ghever C, Sobral RA, Amorim RL, Oliveira LO, Sueiro FAR, Beserra HEO, Bertagnolli AC, Gamba CO, Damasceno KA, Campos CB, Araujo MR, Campos LC, Monteiro LN, Nunes FC, Horta RS, Reis DC, Luvizotto MCR, Magalhães GM, Raposo JB, Ferreira AMR, Tanaka NM, Grandi F, Ubukata R, Batschinski K, Terra EM, Salvador RCL, Jark PC, Delecrodi JER, Nascimento NA, Silva DN, Silva LP, Ferreira KCRS, Frehse MS, di Santis GW, Silva EO, Guim TN, Kerr B, Cintra PP, Silva FBF, Leite JS, Mello MFV, Ferreira MLG, Fukumasu H, Salgado BS, Torres R (2014). Consensus for the diagnosis, prognosis and treatment of canine mammary tumors -2013. Braz. J. Vet. Pathol., 7(2): 38-69.

- Chang CC, Tsai MH, Liao JW, Chan JP, Wong ML, Chang SC (2009). Evaluation of hormone receptor expression for use in predicting survival of female dogs with malignant mammary gland tumors. J. Am. Vet. Med. Assoc., 235(4): 391-396. https://doi.org/10.2460/javma.235.4.391

- Coelho PGB, Souza MV, Conceição LG, Viloria MIV, Bedoya SAO (2018). Evaluation of dermal collagen stained with picrosirius red and examined under polarized light microscopy. An. Bras. Dermatol., 93(3): 415-418. https:// doi.org/10.1590/abd1806-4841.20187544 
- Coleman R (2011). Picrosirius red staining revisited. Acta. Histochem., 113(3): 231-233. https://doi.org/10.1016/j. acthis.2010.02.002

-Elston CW, Ellis IO (1991). Pathological prognostic factors in breast cancer I. The value of histological grade in breast cancer: Experience from a large study with long-term follow-up. Histopathology, 19(5): 403-410. https://doi. org/10.1111/j.1365-2559.1991.tb00229.x

-Ettlin J, Clementi E, Amini P, Malbon A, Markkanen E (2017). Analysis of gene expression signatures in cancer-associated stroma from canine mammary tumours reveals molecular homology to human breast carcinomas. Int. J. Mol. Sci., 18(5): 1101. https://doi.org/10.3390/ijms18051101

- Garcia APV, Reis LA, Nunes FC, Longford FGJ, Frey JG, de Paula AM, Cassali GD (2021). Canine mammary cancer tumour behaviour and patient survival time are associated with collagen fibre characteristics. Sci. Rep., 11(1): 5668. https://doi.org/10.1038/s41598-021-85104-w

- Golaraei A, Kontenis L, Cisek R, Tokarz D, Done SJ, Wilson BC, Barzda V (2016). Changes of collagen ultrastructure in breast cancer tissue determined by second-harmonic generation double Stokes-Mueller polarimetric microscopy. Biomed. Opt. Express, 7(10): 4054-4068. https://doi. org/10.1364/BOE.7.004054

- Green KA, Lund LR (2005). ECM degrading proteases and tissue remodelling in the mammary gland. BioEssays, 27(9): 894-903. https://doi.org/10.1002/bies.20281

-Insua-Rodríguez J, Oskarsson T (2016). The extracellular matrix in breast cancer. Adv. Drug. Deliv. Rev., 97: 41-55. https:// doi.org/10.1016/j.addr.2015.12.017

-Jones CE, Hammer AM, Cho Y, Sizemore GM, Cukierman E, Yee LD, Ghadiali SN, Ostrowski MC, Leight JL (2019). Stromal PTEN regulates extracellular matrix organization in the mammary gland. Neoplasia, 21(1): 132-145. https:// doi.org/10.1016/j.neo.2018.10.010

-Kakkad SM, Solaiyappan M, Argani P, Sukumar S, Jacobs LK, Leibfritz D, Bhujwalla ZM, Glunde K (2012). Collagen I fiber density increases in lymph node positive breast cancers: pilot study. J. Biomed. Opt. 17(11): 116017. https://doi. org/10.1117/1.JBO.17.11.116017

-Karayannopoulou M, Kaldrymidou E, Constantinidis TC, Dessiris A (2005). Histological grading and prognosis in dogs with mammary carcinomas: Application of a human grading method. J. Comp. Path. 133(14): 246-252. https:// doi.org/10.1016/j.jcpa.2005.05.003

-Kauppila S, Stenbäck F, Risteli J, Jukkola A, Risteli L (1998). Aberrant type I and type III collagen gene expressionin human breast cancer in vivo. J. Pathol., 186(3): 262-268. https://doi. org/10.1002/(SICI)1096-9896(1998110)186:3<262::AIDPATH191>3.0.CO;2-3

-Koenig A, Mueller C, Hasel C, Adler G, Menke A (2006). Collagen type $I$ induces disruption of ecadherin- mediated cell-cell contacts and promotes proliferation of pancreatic carcinoma cells. Cancer. Res., 66(9): 4662-4671. https://doi. org/10.1158/0008-5472.CAN-05-2804

-Levental KR, Yu H, Kass L, Lakins JN, Egeblad M, Erler JT, Fong SF, Csiszar K, Giaccia A, Weninger W, Yamauchi M, Gasser DL, Weaver VM (2009). Matrix crosslinking forces tumor progression by enhancing integrin signaling. Cell, 139(5): 891-906. https://doi.org/10.1016/j.cell.2009.10.027

-Luparello C (2013). Aspects of Collagen Changes in Breast Cancer. J. Carcinogene. Mutagene., S13: 007. https://doi. org/10.4172/2157-2518.S13-007
- Lyons TR, O'Brien J, Borges VF, Conklin MW, Keely PJ, Eliceiri KW, Marusyk A, Tan AC, Schedin P (2011). Postpartum mammary gland involution drives progression of ductal carcinoma in situ through collagen and COX-2. Nat. Med., 17(9): 1109-1116. https://doi.org/10.1038/nm.2416

- Maller O, Hansen KC, Lyons TR, Acerbi I, Weaver VM, Prekeris R, Tan AC, Schedin P (2013). Collagen architecture in pregnancy-induced protection from breast cancer. J. Cell. Sci., 126(Pt 18): 4108-4110. https://doi.org/10.1242/ jcs. 121590

- Martins AMCRPF,Tamaso E, Guerra JL (2002). Histochemical study of fibrillar proteins of the extracellular matrix in benign and malignant mammary neoplasms in dogs. Braz. J. vet. Res. Anim. Sci., 39(1): 43-49. https://doi.org/10.1590/ S1413-95962002000100008

-McLean GW, Komiyama NH, Serrels B, Asano H, Reynolds L, Conti F, Hodivala-Dilke K, Metzger D, Chambon P, Grant SG, Frame MC (2004). Specific deletion of focal adhesion kinase suppresses tumor formation and blocks malignant progression. Genes. Dev., 18(24): 2998-3003. https://doi. org/10.1101/gad.316304

- Misdorp W (2002). Tumors of the mammary gland. In: Meuten DJ, ed. Tumors in Domestic Animals. $4^{\text {th }}$ ed. Ames, IA: Iowa State Press, USA, pp. 575-606. https://doi. org/10.1002/9780470376928.ch12

- Miyazaki K, Oyanagi J, Hoshino D, Togo S, Kumagai H, Miyagi Y (2019). Cancer cell migration on elongate protrusions of fibroblasts in collagen matrix. Sci. Rep., 9(1): 292. https:// doi.org/10.1038/s41598-018-36646-z

- Moriggi M, Giussani M, Torretta E, Capitanio D, Sandri M, Leone R, De Palma S, Vasso M, Vozzi G, Tagliabue E, Gelfi C (2018). ECM remodelling in breast cancer with different grade: Contribution of 2D-DIGE proteomics. Proteomics, 18(24): e1800278. https://doi.org/10.1002/pmic.201800278

- Oskarsson T (2013). Extracellular matrix components in breast cancer progression and metastasis. Breast, 22 (Suppl 2): S66-S72. https://doi.org/10.1016/j.breast.2013.07.012

- Paszek MJ, Zahir N, Johnson KR, Lakins JN, Rozenberg GI, Gefen A, Reinhart-King CA, Margulies SS, Dembo M, Boettiger D, Hammer DA, Weaver VM (2005). Tensional homeostasis and the malignant phenotype. Cancer Cell, 8(3): 241-254. https://doi.org/10.1016/j.ccr.2005.08.010

- Pavelski M, Silva DM, Leite NC, Junior DA, de Sousa RS, Guérios SD, Dornbusch PT (2015). Infrared thermography in dogs with mammary tumors and healthy dogs. J. Vet. Int., 29(6): 1578-1583. https://doi.org/10.1111/jvim.13597

-Peña L, De Andrés PJ, Clemente M, Cuesta P, Pérez-Alenza MD (2013). Prognostic value of histological grading in noninflammatory canine mammary carcinomas in a prospective study with two-year follow-up: relationship with clinical and histological characteristics. Vet. Pathol., 50(1): 94-105. https://doi.org/10.1177/0300985812447830

- Perez Alenza MD, Peña L, del Castillo N, Nieto AI (2000). Factors influencing the incidence and prognosis of canine mammary tumours. J. Small. Anim. Pract., 41(7): 287-291. https://doi.org/10.1111/j.1748-5827.2000.tb03203.x

-Provenzano PP, Eliceiri KW, Campbell JM, Inman DR, White JG, Keely PJ (2006). Collagen reorganization at the tumorstromal interface facilitates local invasion. BMC. Med., 4: 38. https://doi.org/10.1186/1741-7015-4-38

- Provenzano PP, Inman DR, Eliceiri KW, Knittel JG, Yan L, Rueden CT, White JG, Keely PJ (2008). Collagen density promotes mammary tumor initiation and progression. BMC 
Med., 6: 11. https://doi.org/10.1186/1741-7015-6-11

- Rasotto R, Berlato D, Goldschmidt MH, Zappulli V (2017). Prognostic significance of canine mammary tumor histologic subtypes: An observational cohort study of 229 cases. Vet. Pathol., 54(4): 571-578. https://doi. org/10.1177/0300985817698208

-Rittié L (2017). Method for picrosirius red-polarization detection of collagen fibers in tissue sections. In: Laure R, ed. Fibrosis: Methods and Protocols, Methods in Molecular Biology. $1^{\text {st }}$ ed. Springer Science+Business Media LLC, 1: 395-407. https://doi.org/10.1007/978-1-4939-7113-8_26

- Shi Q, Ghosh RP, Engelke H, Rycroft C H, Cassereau L, Sethian JA, Weaver VM, Liphardt JT (2014). Rapid disorganization of mechanically interacting systems of mammary acini. PNAS, 111(2): 658-663. https://doi. org/10.1073/pnas.1311312110

- Simon D, Schoenrock D, Nolte I, Baumgärtner W, Barron R, Mischke R (2009). Cytologic examination of fine-needle aspirates from mammary gland tumors in the dog: diagnostic accuracy with comparison to histopathology and association with postoperative outcome. Vet. Clin. Pathol., 38(4): 521528. https://doi.org/10.1111/j.1939-165X.2009.00150.x
- Soler M, Dominguez E, Lucas X, Novellas R, Gomes-Coelho KV, Espada Y, Agut A (2016). Comparison between ultrasonographic findings of benign and malignant canine mammary gland tumours using b-mode, colour doppler, power doppler and spectral doppler. Res. Vet. Sci., pp. 141146. https://doi.org/10.1016/j.rvsc.2016.05.015

-Tavasoly A, Golshahi H, Rezaie A, Farhadi M (2013). Classification and grading of canine malignant mammary tumors. Vet. Res. Forum, 4(1): 25-30.

-Theocharis AD, Skandalis SS, Gialeli C, Karamanos NK (2016). Extracellular matrix structure. Adv. Drug. Del. Rev., 97: 4-27.https://doi.org/10.1016/j.addr.2015.11.001

-van Kempen LC, Ruiter DJ, van Muijen GN, Coussens LM (2003). The tumor microenvironment: a critical determinant of neoplastic evolution. Eur. J. Cell. Biol., 82(11): 539-548. https://doi.org/10.1078/0171-9335-00346

-Wei SC, Fattet L, Tsai JH, Guo Y, Pai VH, Majeski HE, Chen AC, Sah RL, Taylor SS, Engler AJ, Yang J (2015). Matrix stiffness drives epithelial-mesenchymal transition and tumour metastasis through a TWIST1-G3BP2 mechanotransduction pathway. Nat. Cell. Biol., 17(5): 678688. https://doi.org/10.1038/ncb3157 